\title{
Evaluation of Self-Medication Among Pharmacy Students
}

\author{
Suleiman Ibrahim Sharif, \\ Osama Hussein Mohamed Ibrahim, Laila Mouslli and Riham Waisi \\ Department of Pharmacy Practice and Pharmacotherapeutics, \\ College of Pharmacy, University of Sharjah, 27272, United Arab Emirates, Sharjah
}

Received 2012-12-01, Revised 2012-12-05; Accepted 2012-12-15

\begin{abstract}
To determine the incidence of self-medication among Sharjah university students and the impact of medical knowledge on such practice. A pre-validated questionnaire was distributed to 200 pharmacy students during May, 2012. Data were analyzed using SPSS and results expressed as counts and percentages. The overall response rate was $85 \%$ with $98 \%$ of respondents being Arabs. Females comprised about $91 \%$ of students and the mean age (SD) was 19.5(2.4). Practicing self-medication in the past year was high as $145(86 \%)$ used drugs without medical consultation. Most respondents (128, $76 \%)$ obtained their medication from pharmacies and used the medication for one week $(106,63 \%)$. Antibiotics were used by $54(32 \%)$ of students despite the fact that slightly more than $50 \%$ of students were aware of the possibility of emergence of bacterial resistance and were also aware of the concept of rational drug use in general. Main reasons for self-medication were non-serious health problem, illness is minor, seeking quick relief and to avoid long waiting hours at clinics. Reasons against selfmedication include risks of adverse effects, using the wrong medication, drug interaction, misdiagnosis and drug abuse and dependence. Medical consultation is mainly sought in case of presence of severe pain, worsening of symptoms, or persistence of the latter for more than a week. Headache or mild pain, eye and ear symptoms, gastric problems, cold, fever and allergy were the commonest symptoms for self-medication. Knowledge of responsible self medication is inadequate but the practice is high and common among pharmacy students. Interventions to promote responsible self-medication among university students are required.
\end{abstract}

Keywords: United Arab Emirates, Pharmacy Students, Self-Medication

\section{INTRODUCTION}

Self medication is the medically unsolicited use of prescription and/or Over-The Counter (OTC) drugs. The practice is becoming a form of self care (Hughes et al., 2001) and is a global trend that is encouraged when it deals with minor illness (Porteous et al., 2005). Selfmedication is not restricted to OTC drugs, it also encompasses use of prescription drugs like antibiotics (Abasaeed et al., 2009; Sarhroodi et al., 2010). Particularly in countries where there are no strict regulations and prescription drugs are freely dispensed.
Therefore responsible self-medication can be defined as the appropriate use of OTC drugs to conditions for which they are necessary (Annonymus, 2007), a practice that requires a certain level of knowledge by those who use such drugs (Aljinovic-Vucic et al., 2005). The WHO (1995) stressed that rational self medication helps in the prevention and treatment of minor pathological conditions at an affordable cost. However, the practice is not without undesirable and sometimes serious drawbacks. As in addition to the possibility of serious adverse effects, drug interactions, poly pharmacy and drug abuse and dependence, the emergence of resistant

\section{Corresponding Author: Suleiman Ibrahim Sharif, Department of Pharmacy Practice and Pharmacotherapeutics,} College of Pharmacy, University of Sharjah, 27272, United Arab Emirates, Sharjah 
pathogens pose a problem when dealing with misuse of antibiotics (Hughes et al., 2001; Sarhroodi et al., 2010). James et al. (2006) reported numerous reasons for self medication which include high cost of medical consultation, long hours of waiting at clinics, lack of time, social or family support, previous experience with the condition and its drug management and lack of nearby health facilities and unavailability of health professionals. It has been frequently reported that in different populations, university students use selfmedication very often (Sawalha, 2008; Zafar et al., 2008; Klemenc-Ketis et al., 2010). Moreover, medical knowledge has been shown to influence self-medication (James et al., 2006; Sawalha, 2008; Klemenc-Ketis et al., 2010). Self-medication among university students in the United Arab Emirates has not, to our knowledge, been previously explored. The present study was undertaken to evaluate self-medication practice among students of the Sharjah-pharmacy students and assess the impact of knowledge about drugs and diseases on such practice.

\section{MATERIALS AND METHODS}

This anonymous questionnaire-based study was carried out during May, 2012, using a pre-validated questionnaire consisting of both open-ended and closedended item as modified from questionnaires used in other studies (James et al., 2006; Klemenc-Ketis et al., 2010). The study was approved by the research and Ethics Committee of the Colleges of Medicine and Health Sciences, University of Sharjah, United Arab Emirates. The questionnaire was first pre-validated on a sample of 12 students and it was in English. It was distributed to a total of 200 students of third pharmacy at the University of Sharjah. The use of prescription or OTC drugs without medical consultation was considered self-medication and the questionnaire was explained to all students participating in the study. Students were asked to report self-medication in the past year. The questionnaire contained questions covering demographic information namely age, sex, nationality, college and year of study and questions focusing on self-medication. The latter included self-medication practice, types of self-medications used, duration of use, source of drugs, use of antibiotics, reasons for and against self-medication and reasons for seeking medical consultation. The questions also addressed views of students on self-medication, health conditions requiring self-medication and the medications used.

Descriptive statistics were calculated using SPSS program version 18. The data were summarized as percentages and frequencies.

\section{RESULTS}

The questionnaire was completed by 169 students (response rate $85 \%$ ). Ninety eight percent of the students were Arabs with $10 \%$ UAE nationals. The mean age \pm S.D. of the respondents was $19.5 \pm 2.4$ (range 18-23). The number of females $(153,91 \%)$ was far in excess of male $(16,9 \%)$ students. Self-medication practice in the past year, duration of use, source of medication and self-use of antibiotics are shown in Table 1. Large number of students $(145,86 \%)$ practiced self-medication in the past year and the majority $(128,76 \%)$ obtained their medications from pharmacies. About one third of students used antibiotics for self-medication and slightly more than $50 \%$ of students were aware of rational drug use and the possibility of development of bacterial resistance associated with misuse of antibiotics. Responses on reasons for self-medication are shown in Table 2. These include health problem is not serious, illness is minor, seeking quick relief and avoidance of long waiting at clinics. On the other hand, reasons against selfmedication focused on risks of adverse effects, use of wrong medication, drug interaction, misdiagnosis of condition and drug abuse and dependence.

Table 1. Self- medication practice by pharmacy students in the past year

\begin{tabular}{|c|c|c|}
\hline & $\begin{array}{l}\text { No. of } \\
\text { respondents }\end{array}$ & Percentage \\
\hline \multicolumn{3}{|c|}{ Did you use self-medication } \\
\hline Yes & 145 & 86 \\
\hline \multicolumn{3}{|l|}{ How long the } \\
\hline One week & 106 & 63 \\
\hline Two weeks & 21 & 12 \\
\hline One month & 6 & 4 \\
\hline Longer than a month & 10 & 8 \\
\hline \multicolumn{3}{|c|}{$\begin{array}{l}\text { Where from you } \\
\text { obtained self-medication? }\end{array}$} \\
\hline Pharmacy & 128 & 76 \\
\hline Street market & 12 & 7 \\
\hline Herbal store & 13 & 8 \\
\hline Relative/friend & 21 & 12 \\
\hline \multicolumn{3}{|l|}{ Antibiotic obtained } \\
\hline Yes & 54 & 32 \\
\hline No & 94 & $5 \overline{6}$ \\
\hline \multicolumn{3}{|l|}{ Duration of use. } \\
\hline One week & 42 & 25 \\
\hline Two weeks & 15 & 9 \\
\hline \multicolumn{3}{|l|}{ Awareness of } \\
\hline \multicolumn{3}{|l|}{ bacterial resistance. } \\
\hline Not aware & 80 & 47 \\
\hline \multicolumn{3}{|l|}{$\begin{array}{l}\text { Awareness of } \\
\text { rational drug use. }\end{array}$} \\
\hline Aware & 90 & 53 \\
\hline Not aware & 124 & 73 \\
\hline
\end{tabular}

Total number of respondents $(n=169)$ 
Table 2. Reasons for self-medication

\begin{tabular}{lcc}
\hline & No. of respondents & Percentage \\
\hline Health problem is not serious & 122 & 72 \\
Seeking quick relief & 88 & 52 \\
Personal convenience & 48 & 28 \\
Avoidance of long waiting at clinics & 52 & 31 \\
High cost of medical consultation & 27 & 16 \\
Suggestion of a relative/friend & 26 & 15 \\
Learning opportunity & 10 & 6 \\
Self need to play active role & 15 & 9 \\
Physician's advice of self management & 17 & 10 \\
Physician prescription was not effective & 7 & 4 \\
I do not trust my physician & 9 & 5 \\
Illness is minor & 88 & 52 \\
Embarrassed of discussing own symptoms & 11 & 7
\end{tabular}

Total number of respondents $(\mathrm{n}=169)$

Table 3. Reasons against self-medication and reasons for seeking professional help

\begin{tabular}{lcc}
\hline & No. of respondents & Percentage \\
\hline Reasons against self-medication & & \\
Risk of adverse effects & 105 & 62 \\
Risk of using wrong medication & 104 & 62 \\
Risk of misdiagnosis of illness & 61 & 36 \\
Risk of drug interaction & 64 & 38 \\
Risk of drug abuse and dependence & 50 & 30 \\
Reasons for seeking professional help & 101 & 60 \\
-Presence of severe pain & 79 & 47 \\
-Symptoms last for more than one week. & 103 & 61 \\
-Symptoms are worsening & 64 & 38 \\
-Thinking the problem is serious. & 42 & 25 \\
-Usual treatment is not effective. & 22 & 13 \\
-Side effects of usual treatment. & 10 & 6 \\
-In case of mental problem & & \\
\hline
\end{tabular}

Total number of respondents $(\mathrm{n}=169)$

Table 4. Student's views on some aspects of self-medication

\begin{tabular}{lrr}
\hline & $\begin{array}{c}\text { Approve } \\
\text { No. of respondents }\end{array}$ & $\begin{array}{c}\text { Disapprove } \\
(\%)\end{array}$ \\
\hline -All medications (prescription, & $70(41)$ & $65(39)$ \\
OTC and herbal) have adverse effects. & $80(47)$ & $80(47)$ \\
-Concomitant use of drugs can be dangerous. & $124(73)$ & $36(21)$ \\
-Increasing drug dose can be dangerous. & $47(28)$ & $53(31)$ \\
-Decreasing drug dose can be dangerous. & $102(60)$ & $75(44)$ \\
-In case of adverse effects, physician help must be sought. & $111(66)$ & $68(40)$ \\
-Using medications with unknown & & \\
Substances in patients with liver and & $57(34)$ & $105(62)$ \\
kidney disease is dangerous. & $71(42)$ & $83(49)$ \\
-No drug can be used during pregnancy. & $80(47)$ & $64(38)$ \\
-Mild medical problems do not require drug treatment. & & \\
-Self-medication can mask signs and symptoms & & \\
of disease so the physician can over look them easily. & & \\
\hline Tol
\end{tabular}


Participants stated that they seek medical consultation if symptoms worsen or persist for more than and in case of severe pain or thinking the problem is serious (Table 3). Student's views on some aspects of self-medication are shown in Table 4. Symptoms for which self-medication was practiced include headache or mild pain, eye and ear symptoms, gastric problems, cold, fever and allergy. The most common types of selfmedications used by participants include analgesics, $(70 \%)$, antipyretic $(67 \%)$, vitamins and minerals $(67 \%)$, herbal teas (40\%), eye drops (33\%) and ear drops (30\%), anti-histamines (20\%), nasal decongestants (20\%), antacids (20\%), laxatives (10\%), anti-diarrheal(1\%) and anti-emetics (1\%).

\section{DISCUSSION}

The majority of Sharjah-pharmacy students participating in the present study were female Arabs who have been exposed to courses on drugs and diseases. Self-medication among students seems to be common practice for non serious health problems, to seek quick relief and for minor illness. In the present study, prevalence of self-medication is rather high such prevalence is reminiscent to the trend in Pakistani (Mumtaz et al., 2009) but higher than that in Bahraini (James et al., 2006) students. It is worth noting that Martins et al. (2002) reported prevalence rates as low as $26.2 \%$ in Portugal whereas higher rates (92\%) were observed by Abahusain et al. (2005) in Kuwait. It has been claimed that the incidence of self-medication is dependent on how the question was constructed in the questionnaire (Almasdy and Sharrif, 2011) where questioning current practice yield high rates (Sawalha, 2008; Zafar et al., 2008; Klemenc-Ketis et al., 2010; James et al., 2006; Verma et al., 2010; Ali et al., 2010) and questioning past practice yield low rates (James et al., 2006; Hussain and Khanum, 2008). Our results do not support such claims as our students were asked to report on past year self-medication practice and the incidence rate was markedly high reaching $86 \%$.

Abahusain et al. (2005) reported on differences in self-medication between male and female high school students. Since in the present study $91 \%$ of the participants were females, no attempts were made to study the gender-based differences, if any, on selfmedication frequency. Most respondents used selfmedication for one week; however, $8 \%$ of respondents practiced self-medication for longer than a month. Despite the fact that it is only reported by a small number of respondents such a lengthy self-medication practice warrants in-depth further investigation as it could be traced back to misdiagnosis of condition or to the use of the wrong medication. The main source for obtaining medicines was the pharmacy and only a few respondents obtained their medications from other sources including street market, herbal stores and relatives or friends. This is in accordance with results of earlier studies (James et al., 2006; Zafar et al., 2008; Klemenc-Ketis et al., 2010). Alarmingly, about one third of the respondents obtained antibiotics for selfmedication without a prescription despite the fact that they were aware of the risk of development of bacterial resistance. This is similar to the results reported for Jordanian (Sawair et al., 2009) and Iranian (Sarhroodi et al., 2010) students. Such a trend is probably due to the fact that regardless of the strict regulations of health authorities in UAE, antibiotics, like other most prescription drugs, can still be obtained without a prescription.

Results of the present study indicate that in agreement with previous studies (Sawalha, 2008; Zafar et al., 2008; Klemenc-Ketis et al., 2010; James et al., 2008; Ghosh et al., 2010), the main reasons for self-medication include health problem being not serious, the illness is minor, to get quick relief of the condition and to avoid long waiting at clinics. Similarly, our results for reasons against self-medication were in agreement with those reported for university students in other countries (James et al., 2006; Sontakke et al., 2011; Olayemi et al., 2010). Risks of adverse effects and using wrong medication were ranked as the main reasons deterring respondents from practicing self-medication while risks of misdiagnosing the condition, drug interaction and drug abuse and dependence were ranked second. Surprisingly a large number (range 21-62\%) of students disapproved the concepts that prescription and OTC drugs and herbal preparation have adverse effects, decreasing or increasing the drug dose or concomitant use of drugs may be dangerous, physician's help should be sought in case of adverse effects, using medication with unknown substance in presence of renal or liver disease can be dangerous, minor problems may not require drug treatment and self-medication may mask symptoms of a disease. These responses by third year pharmacy students points at the need to stress on such important aspects on the use of prescription drugs, OTC and herbal preparation in various relevant courses of pharmacy practice and pharmacology. A very alarming observation is the use of antibiotics for self-medication by one third of the participants despite their knowledge of the possibility of development of bacterial resistance. This issue requires more attention of both the academic 
and health authorities in attempts to increase awareness of not only students but also the general public to the rational use of antibiotics. Similar to earlier studies (Hughes et al., 2001; James et al., 2006; Sawalha, 2008; Zafar et al., 2008) symptoms for which self-medication was practiced include headache or mild pain, eye and ear symptoms, gastric problems, cold, fever and allergy. The most common types of self-medications used by participants include analgesics, vitamins and minerals, herbal teas, eye and ear drops, antihistamines, nasal decongestants, antacids, laxatives, anti-diarrheal and anti-emetics.

\section{CONCLUSION}

The prevalence of self-medication among pharmacy students at Sharjah University is high. Knowledge of students of reasons for and against self-medication seems appropriate. However, more efforts to promote responsible self-medication by inclusion in the curricula of topics/courses dealing with rational drug and antibiotic use and general aspects of self-medication are needed. In addition, health authorities should practice more strict control over pharmacies.

\section{ACKNOWLEDGMENT}

The researchers would like to thank the students of the college of pharmacy, at the University of Sharjah for their valuable help in this study.

\section{REFERENCES}

Abahusain, E., L.K. Matowe and P.J. Nicholls, 2005. Self-reported medication use among adolescents in Kuwait. Med. Princ. Pract., 14: 161-164. DOI: 10.1159/000084633

Abasaeed, A., V. Jiri, A. Mohammed and K. Ales, 2009. Self-medication with antibiotics by the community of Abu Dhabi Emirate, United Arab Emirates. J. Infect. Dev. Ctries, 3: 491-497. PMID: 19762966

Ali, S.E., M.I.M. Ibrahim and S. Palaian, 2010. Medication storage and self-medication behavior amongst female students in Malaysia. Pharm. Pract., 8: 226-232.

Aljinovic-Vucic, V., V. Trkulja and Z. Lackovic, 2005. Content of home pharmacies and self-medication practices households of pharmacy and medical students in Zagreb, Croatia; findings in 2001 with reference to 1977. Croat. Med. J., 46: 74-80. PMID: 15726679
Almasdy, D. and A. Sharrif, 2011. Self-medication practice with nonprescription medication among university students: A review of the literature. Arch. Pharm. Pract., 2: 95-100.

Annonymus, 2007. World Self-Medication Industry: responsible self-care and self-medication. A worldwide review of consumer surveys.

Ghosh, S., V. Vikas, A. Gupta and R. Chaudhary, 2010. Evaluation of the practice of self-medication among college students in west Uttar Pradesh. Int. J. Pharm. Profess. Res., 1: 14-18.

Hughes, C.M., J.C. McElnay and G.F. Fleming, 2001. Benefits and risks of self-medication. Drug Saf., 24: 1027-1037. PMID: 11735659

Hussain, A. and A. Khanum, 2008. Self-medication among university students of Islamabad, Pakistan-a preliminary study. Southern Med. Rev., 1: 14-16.

James, H., S.S. Handu, K.A.J. Al-Khaja and R.P. Sequeira, 2008. Influence of medical training on self-medication by students. Int. J. Clin. Pharmacol. Ther., 46: 23-29. DOI: 10.5414/CPP46023

James, H., S.S. Handu, K.A.J. AlKhaja, S. Otoom and R.P. Sequeira, 2006. Evaluation of the knowledge, attitude and practice of self-medication among firstyear medical students. Med. Princ. Pract., 15: 270275. DOI: $10.1159 / 000092989$

Klemenc-Ketis, Z., Z. Hladnik and J. Kersnik, 2010. Self-medication among healthcare and nonhealthcare students at university of Ljubljana, Slovenia. Med. Princ. Pract., 19: 395-401. DOI: 10.1159/000316380

Martins, A.P., A.C. Miranda, Z. Mendes, M.A. Soares and P. Ferreira et al., 2002. Self-medication in a Portuguese urban population: A prevalence study. Pharmacoepidemiol. Drug Saf., 11: 409-414. DOI: 10.1002/pds.711

Mumtaz, Y., S.M.A. Jahangeer, T. Mujtaba, S. Zafar and S. Adnan, 2009. Self medication among university students of Karachi. JLUMHS, 10: 102-105.

Olayemi, O.J., B.O. Olayinka and A.I. Musa, 2010. Evaluation of antibiotic self-medication pattern amongst undergraduate students of Ahmadu Bello university (main campus), Zaria. Res. J. Applied Sci. Eng. Technol., 2: 35-38.

Porteous, T., C. Bond, P. Hannaford and H. Sinclair, 2005. How and why are non-prescription analgesics used in Scotland? Fam. Pract., 22: 78-85. DOI: 10.1093/fampra/cmh719 
Sarhroodi, S., A. Arzi, A.F. Swalha and A. Ashtranezhad, 2010. Antibiotic self-medication among southern Iranian university students. Int. J. Pharmacol., 6: 48-52.

Sawair, F.A., A. Baqain, A.A. Karaky and R.A. Eid, 2009. Assessment of self-medication of antibiotics in a Jordanian population. Med. Princ. Pract., 18: 21-25. DOI: 10.1159/000163041

Sawalha, A.F., 2008. Adescriptive study of selfmedication practices among Palestinian medical and non-medical university students. Res. Soc. Adm. Pharm., 4: 164-172. DOI: 10.1016/j.sapharm.2007.04.004

Sontakke, S.D., C.S. Bajait, S.A. Pimpalkhute, K.M. Jaiswal and S.R. Jaiswal, 2011. Comparative study of evaluation of self-medication practices in first and third year medical students. Int. J. Biol. Med. Res., 2: $561-564$.
Verma, R.K., L. Mohan and M. Pandey, 2010. Evaluation of self medication among professional students in North India: Proper statutory drug control must be implemented. Asian J. Pharmaceut. Clin. Res., 3: 60-64.

WHO, 1995. Report of the WHO Expert Committee on National Drug Policies. 1st Edn., World Health Organization, Geneva, pp: 78.

Zafar, S.N., R. Syed, S. Wagar, A.J. Zubairi and T. Vagar et al., 2008. Self-medication amongst university students of Karachi: prevalence, knowledge and attitudes. J. Pak. Med. Assoc., 58: 214-217. PMID: 18655436 